narcosis is due to temporary exclusion of the cerebral cortex from the reflex circuit is difficult to reconcile with the absence of any such effect during the narcosis pro. duced by many other drugs. Link suggests that this objection may be met on the hypothesis that some narcotic drugs possess specific properties in addition to their general narcotic action. 'Illustrative of this are Finkelenburg's ${ }^{6}$ observations that the injection of cocaine into the spinal canal leaves the reflexes unchanged; whilst if stovaine be injected, the deep reflexes first and subsequently the skin reflexes are abolished. Even in the rare instances of stovaine narcosis, in which the tendon reflexes are increased, the Babinski extensor response never occurs. The selective power of modifying the spinal reflexes thus shown to be inherent in some drugs affords a possible clue to the manner in which the variations in the symptoms were produced in the case first described. The drug produces very decided results, but they are limited to the effective period of each dose; when the influence of the drug passes off, the reflexes revert to the normal type. Assuming that an autogenous toxin is the causal agent by which disseminate sclerosis is developed, it may be further assumed that, in the early stages of the disease, the toxin is produced intermittently and that it may derange the function of the implicated nerve structures before any recognizable anatomical changes are produced. Such disturbance of function would occur in waves corresponding to the intermittent evolution of the toxin; and being merely a "functional disorder," would subside as each batch of toxin was exhausted. Under such conditions, the rapid oscillations in the symptoms and reflexes would be accounted for.

The course of the symptoms in the second of the two cases is in marked contrast with that observed in the first. Instead of rapid interchanges between the symptoms and their entire subsidence in a few months, was comparative constancy and prolonged duration with paralysis extending over years. This is suggestive of physical changes, and yet the paralysis, along with the other symptoms, vanished. Cases of this kind point to the possibility of regenerative processes taking place in organically damaged areas. The lengthy persistence of the symptoms and abnormal reflexes with ultimate recovery is scarcely explicable on any other hypothesis. That the disease will eventually recur and be progressive is, unfortunately, more than probable; meanwhile, the symptoms have been in abeyance for upwards of twelve months.

1 Deut. med. Woch., 1903. 2 Ibid., 1904. ${ }^{3}$ Zeitschr.f. klin. Med., 1906. Neurolog. Centralbi., 1903. 5 Deut. med. Woch., 1904. 6 Münch. med. och, 1906 .

\section{A CASE OF CONVULSIVE TIC.}

By T. W. EDMONDSTON ROSS, M.D., F.R.C.S.E., CARDIFF.

TнE following case is perhaps of sufficient interest to warrant publication :

L. S., a boy, aged 11, had always been considered robust and healthy, and had no illness, except measles when he was a year old. His general characteristics were those of an unusually intelligent child of a somewhat serious disposition. His father and mother are healthy; they have two younger children, both healthy. There is no history of epilepsy nor insanity, nor of any grave nervous disorder in the family of either parent.

In May, 1907, he suffered from chicken-pox. During this illness the mother noticed that he occasionally jerked his head. to one or other side, and sometimes also jerked his arms about. This was thought to be St. Vitus's dance, and little attention was paid to it, although it persisted.

Early in January, 1908, the boy came under observation suffering from acute otitis media. Examination of the ear was rendered difficult by the restlessness of the patient. The head was constantly and forcibly jerked towards either shoulder, generally the right, whilst the head was rotated with : the chin towards the opposite shoulder. These movements the chin towards the opposite shoulder. These movements or a sharp, squeaking cry. The arms were frequently thrown or a sharp, squeaking cry. The arms were frequently thrown outwards into the abducted position, or forcibly extended as the arms were folded across the chest. The power of speech was unaffected, and the patient could walk well, the leg muscles being unaffected.

On February 3rd, 1908, he developed a severe attack of scarlet fever complicated in its later stages by suppuration in several cervical glands. During the period of severe illness the spasmodic movements never entirely ceased but were not much in evidence.
In April, 1908, when he had got over his other troubles and was beginning to go about again, the spasmodic movements became more marked and certain new phenomena appeared. The facial muscles were affected by spasm, leading to various The facial muscles were affected by spasm, leading to various grimaces accompanying the other movements of the head. panied by a sharp and deep inspiration, were frequent. The panied by a sharp and deep inspiration, were frequent. The trunk muscles were more generally affected, leading to various irregular, forcible twisting movements of the body. The legs ing at something. He could still walk, but often had a difficulty in starting, as spasms of the leg muscles caused a series of preliminary jumps and kicks.

In July, 1908, explosive utterances, both inarticulate and articulate, became prominent. Hiccoughing sounds were the most common, but sounds imitative of dogs, cats and pigs were heard. Exclamations such as "dash!" "bosh!" "go on!" and "damn!" were shouted, often with wearisome persistency. These exclamations usually, but not always, accompanied the other muscular spasms. The power of co-ordinate movement was not interfered with, except at the actual moment of a was not interfered with, except at the actual moment of a spasm. The boy could dress himself, feed himself, write and practise the piano. He could drink from a full glass of water without spilling any, provided the glass was not upset by pre-
liminary flourishes of the arm in the effort to grasp it. During sleep there were no unusual movements.

Since July, 1908, the condition has varied in severity from week to week, but on the whole has steadily got worse.

At the present time (February, 1909) the boy is in good physical condition, and is stouter and strongec than he was six months ago. There is no evidence of organic trouble in any of the systems, nor in the organs of special sense. The only abnormality noted has been a slight exaggeration of the superficial and tendon reflexes.

The spasmodic movements are extremely variable, very irregular in character, and of very constant occurrence, though irreguiar in character, and of very constant occurrence, or two. occasionally the boy may be perfectly still for an hour or fwo. As instances of the force of the spasms, he has broken a fairly strong plate in two whilst holding it in his hands, and often undressing. He often bruises himself with his clenched fist.

undressing. He often bruises himself with his clenched fist. His power of walking is now often interfered with, progression being made by a series of jumps. Sometimes, however, he can walk fairly well, except for an occasional kick with either leg. making life intolerable for the boy and his parents, and constituting a serious nuisance to neighbours.

His exclamations now include such words as "bloody" and "buggar." These occur not only as loud shouts accompanying spasms, but also in ordinary conversation interspersed with the other words. The boy says he does not want to use these words, but that they come to his tongue, and he must say them. He often repeats any observation made to him, in part or in whole. Generally one or two words are repeated several or in whole. Generally one or two words are repeated several times, more rarely a whole sentence. When reading to hims

may suddenly shout out a word or a part of a sentence. He has frequently been heard to give involuntary expression
to what is passing in his mind. For example, whilst thanking to what is passing in his mind. For example, whilst thanking a comparative stranger for a small gift, he has suddenly this, it's not much good."

The boy's moral character has also changed. Formerly particular about his personal appearance, he now takes no pride in being tidy, and says it is too much bother to wash and brush himself, and so forth.

He has become very irritable, especially with other children, and whilst previously very obedient, he is now ready to resent interference. If he be reprimanded about anything, the result is a severe attack of shouting and jumping, perhaps lasting for an hour or two. No mental obsessions have been apparent so far.

From the foregoing account it is evident that this case is an example of convulsive tic of the particular variety known as "Gilles de la Tourette's Disease." There are present :

1. The rapid, forcible, arrhythmic, and involuntary contractions of various muscles or groups of muscles, including those of phonation and respiration.

2. Explosive utterance, articulate and inarticulate.

3. The use of bad language-" Coprolalia."

4. The repetition of words or phrases-"Echolalia."

The results of treatment have, so far, been unsatisfactory. Modified Weir Mitchell treatment produced no benefit. A prolonged change to a quiet country place was without good effect. Drugs of various kinds, including strychnine and arsenic, have been of no avail. Bromides produce a temporary improvement, and a small dose has been given nightly for some weeks past, as otherwise the boy gets almost no sleep, and there is consequently no rest for any other member of the household. An attempt has been made to keep the boy occupied, and to interest him in reading, drawing, music, physical exercises, etc. Whilst so occupied he is often comparatively quiet, but the period of quiescence is usually followed by a severe attack of spasms and shouting. 
The most noteworthy feature of this case appears to be the occurrence of this malady in a strong and otherwise healthy boy, in whose family no history of nervous disease can be obtained.

THE RELATIVE ADVANTAGES OF CATHETERIZATION AND OPERATION IN THE TREATMEN'T OF PROSTATIC ENLARGEMENT.

By HERBERT T. HERRING, M.B., B.S., LONDON.

DURING the last ten years the operation of prostatectomywhich had previously fallen into disrepute-has been revived, owing largely to the advocacy of $\mathrm{Mr}$. Freyer, who has published long lists of successful cases; and it is now accepted as the routine method of treating all sufferers from enlarged prostate. Signs are not wanting, however, of a coming revulsion in favour of a less drastic treatment, namely, the habitual use of the catheter. There are, apparently, two principal causes for this:

1. The serious nature of the operation, and the existence of doubt as to its after.effects; both immediate and remote.

2. The good results obtained from sterile catheterization. I.

The operation of prostatectomy is severe and the mor tality, even with modern improvements, is not less than 10 per cent., and would be far higher if every case throughout the country were recorded. It necessitates prolonged confinement to bed; six weeks would not be overstating the time required for convalescence, and six months must elapse before the patient's health and strength are completely established. Moreover, it is usually performed when the expectation of life is not long, and the sacrifice then of six months, part of which is spent in considerable discomfort, is a matter of consequence. Finally, there remains the all-important question that has never been answered as far as I am aware, What is the proportion of complete cures of those who survive the operation? Innumerable records have been published of the condition of patients six weeks or two months afterwards, but with the exception of 32 cases recorded by $\mathbf{M r}$. W. G. Richardson, ${ }^{1}$ no statistics are forthcoming of the state of those same cases at the end of two years or more.

From my experience, both in regard to patients on whom I have operated and those I have seen after prostatectomy by other surgeons, as well as from isolated reports fur. nished by friends, I have no hesitation in saying-and I believe this will be corroborated by others-that, brilliant as this operation sometimes is, it does not invariably relieve patients of their urinary troubles, and sometimes ends in miserable failure. During the last few months I have collected particulars of the following cases:

A large phosphatic calculus removed a year after prostatectomy.

Two cases of suprapubic fistula

One case of great irritability of bladder both by day and night, as bad as or even worse than that caused by partial retention.

One case of vesical haemorrhage.

Four cases in which the urine was still septic.

I cannot say, of course, whether these cases had been reported as successful or not; yet they suffice to prove that a proportion of patients passing out of the surgeon's care continue to suffer from urinary troubles. Until it is clearly proved that comparatively few suffer from aftertroubles we should not too lightly advise a patient to submit to prostatectomy. In the successful cases the patient is freed once and for all from the ties of catheter life, which is a very great advantage and appeals strongly to very many.

II.

In the alternative treatment-the habitual use of the catheter-there is little or no danger to life, and no 10 per cent. mortality to face, provided sterility is main. tained. The patient after two or three days' rest, while learning the art of sterile catheterization, is able to resume his ordinary occupation. His health is not in any way impaired by long confinement; in fact, a general improvement begins directly the bladder is emptied and he is relieved of the nocturnal frequency. With the exception of having to use the catheter two, three, or four times in the twenty-four hours for the rest of his life-the premium he pays for escaping operation-he has nothing to fear.
This statement will be challenged, for everyone has seen the terrible local and constitutional symptoms which more often than not follow the use of the catheter. But those symptoms, the manifestation of cystitis and similar inflammatory processes, are due to sepsis alone; and since they occur so frequently after instrumentation, the inference must be that the micro organisms have gained access to the urinary passages by the agency of such instruments, and therefore that the preparation of the catheter, or the manner in which it has been introduced, is at fault. If, in the past, disaster has attended the use of the catheter, then it is time that some more efficient method of sterilization should be adopted, for success or failure depends entirely on this point. If it is possible to maintain sterilization with certainty, then it appears that catheter life is preferable to operation in the majority of cases of prostatic retention.

The introduction of soft gum elastic catheters into this country some seventy years ago greatly benefited those who used them, but they also rendered the problem of cleanliness more difficult. The old-fashioned metal instrument, with its brightly polished surface, was more readily cleaned and did less harm on that account than the painless and easy-passing soft catheter, with its cotton or silk founda. tion coated with layers of varnish. The same danger exists to day; chemical antiseptics, now so universally. employed, will possibly sterilize the metal, but certainly not soft instruments, for the rough and oil-sodden interior alone offers to the micro-organisms a safe harbour against all chemical action for an indefinite time. Soft instruments prepared in this way cannot be safe, and their use for the treatment of prostatic retention will end sooner or later in failure-that is, in contamination of the urine or tissues. India-rubber catheters are as bad, for though the lumen is not rough and the material offers less pro. tection to the organisms, yet they swell under the influence of grease, become sticky, lose their polish, and moreover require much fingering on account of their extreme flexibility.

The easiest and safest method of producing sterility is by boiling every instrument in water, and in my opinion catheterization as a method of treating prostatic retention is not given a fair trial unless this precaution is taken. There are, however, certain other points which must be attended to, if success is to be attained:

The lubricant must be boiled and applied mechanically, and not with the fingers.

The catheter must be introduced with a minimum amount of handling; certainly the first 4 in, which pass through the prostate, should never be touched.

The fingers of the operator and the orifice of the penis must be scrupulously clean.

These few details the patient must learn before he can be trusted to relieve himself with the catbeter. In order to demonstrate what may be accomplished by a systematic use of the catheter sterilized by boiling, I venture to record the cases which have come under my care during the past year. The results are not perfect, for the limitation. of the use of the catheter has not been reached, and improvements in the method can and will be achieved in the course of time, yet they indicate that a man may lead an active life in comfort, even if he is compelled to use a catheter, and may live to a very ripe old age without the terrible symptoms which have been witnessed in the past. All are living at the present time. The youngest patient is 46 and the oldest 96 . The average age is just under 70: The longest time for which the catheter has been used is forty years, and the average of the series seven years. Most were septic when the treatment began, very often with foul urine and grave constitutional symptoms, and all invariably improved rapidly, as the records show.

The list is divided into three classes :

(a) Those who have recovered the power of naturaI micturition after treatment.

(b) Those who pass their water partly naturally and partly by the catheter.

(c) Those who have to rely on the catheter alone.

In the first two classes the gradual fall in amount of the residual urine in some instances is worthy of note. The bladder seems to regain its power to some extent under the infuence of regular catheterization (Cases III, 1v, v, vI, etc.). For example, the residual urine may be $12 \mathrm{oz}$. at tirst, and after a week or two it will fall to 6 or $7 \mathrm{oz}$., or eren may' 